\title{
Pengaruh Pencahayaan Ruang Kerja Terhadap Stres Kerja Karyawan Biro Perencanaan dan Kerjasama Universitas Sumatera Utara
}

\author{
Effect of Work Space Lighting on Employee Job Stress at Biro \\ Perencanaan dan Kerjasama of the University of North Sumatra
}

\author{
Findy Suri* Emmy Mariatin** \\ *Universitas Medan Area **Universitas Sumatera Utara, Indonesia \\ *Corresponding author: E-mail: *findysuri@gmail.com
}

\begin{abstract}
Abstrak
Stres kerja yang dialami karyawan dapat merugikan perusahaan ataupun organisasi tempatnya bekerja. Lingkungan kerja yang baik dan nyaman dapat menurunkan stress kerja karyawan sehingga karyawan dapat bekerja maksimal. Pencahayaan ruang kerja merupakan faktor penting pada lingkungan kerja. Intensitas cahaya yang sesuai membuat karyawan nyaman dan stress kerja berkurang. Tujuan dari penelitian ini adalah untuk mengetahui pengaruh pencahayaan ruang kerja terhadap stress kerja karyawan Biro Perencanaan dan Kerjasama Universitas Sumatera Utara. Metode yang digunakan pada penelitian ini yaitu pendekatan kuantitatif dengan metode kuasi eksperimen. Desain yang digunakan adalah one group pretest-posttest design. Pada saat pretest, diberikan skala stress kerja kepada subjek penelitian dan pencahayaan ruang kerja diukur dengan menggunakan lux meter. Kemudian intensitas cahaya ruang kerja dinaikkan dan diukur kembali dengan menggunakan lux meter. Setelah diberi tenggang waktu selama satu minggu, diadakan posttest dengan memberikan kembali skala stress kerja kepada subjek penelitian seperti pada saat pretest. Hasil penelitian menunjukkan bahwa stress kerja pada karyawan Biro Perencanaan dan Kerjasama Univeritas Sumatera Utara mengalami penurunan setelah intensitas pencahayaan ruang kerja dinaikkan. Hasil analisis statistik dengan menggunakan paired sample $t$-test menunjukkan t-hitung sebesar 5.179 dengan tingkat Sig (2-tailed) $=0.000$ pada $\mathrm{df}=\mathrm{N}-1=13-1=12$ dengan nilai t-tabel $=2.179$. keputusan : t-hitung $>\mathrm{t}$ tabel atau [5.179 > 2.179] maka Ho ditolak dan Ha diterima artinya ada pengaruh pencahayaan ruang kerja terhadap stress kerja karyawan Biro Perencanaan dan Kerjasama Universitas Sumatera Utara.
\end{abstract}

Kata Kunci: lux meter; pencahayaan ruang kerja; stres kerja.

\begin{abstract}
Job stress experienced by employees can be harming for the company or organization where they worked. The right and comfort work place can reduce stress on employee so that employees can work optimally. Lighting workspace is an important factor in the work environment. The right intensity of light that make employees comfortable fit and reduced job stress. This study aims to explain is there any effect of workspace lighting to employee job stress at Biro Perencanaan dan Kerjasama of the University of North Sumatra. This study uses a quantitative approach with the quasi-experimental methods. The design used was one group pretest-posttest design. At pretest, a job stres scale given to the subject of research and work space illumination was measured using a lux meter. Then the work space light intensity is increased and remeasured by using a lux meter. Then a grace period for one week was given. Then in a posttest condition, a job stress scale was given to research subjects like in pretest condition. The results showed that job stress on Biro Perencanaan dan Kerjasama of the University of North Sumatra decreased after the light intensity of work space is increased. The results of statistical analysis using paired sample t-test showed t count for 5.179 to the level of Sig (2-tailed) $=0.000$ at $d f=N-1=13-1=12$ with $t$-value $=2.179$ tables. decision: $t$ count $>t$ table or [5.179> 2.179] then Ho is rejected and Ha accepted means there is the effect of workspace lighting on employee job stress.

Keywords: job stress; lux meters; workspace lighting
\end{abstract}

How to Cite: Findy,S. \& Emmy, M. 2017 ,Pengaruh Pencahayaan Ruang Kerja Terhadap Stres Kerja Karyawan Biro Perencaan dan Kerjasama Universitas Sumetera Utara, Jurnal Diversita, 3(2): 9-14. 
Suri, F., \& Mariatin, E., 2017. Pengaruh Pencahayaan Ruang Kerja terhadap Stres Kerja Karyawan.

\section{PENDAHULUAN}

Seiring dengan persaingan perusahaan yang semakin berkembang dan menuntut kinerja yang semakin maksimal, hal ini sangat berpengaruh besar terhadap stress kerja. Perusahaan rela melakukan hal apa saja agar dapat bertahan dan menghindari kebangkrutan yang dapat timbul sebagai dampak dari krisis yang berkepanjangan. Tuntutan dari perusahaan inilah yang dapat menyebabkan karyawan merasa stres.

Stres didefinisikan sebagai bentuk reaksi tubuh terhadap masalah dan tekanan. Ini adalah hasil dari ketidakseimbangan antara batin kita sumber daya dan keterampilan di satu sisi, dan tekanan kita hadapi dan dukungan yang diterima untuk menangani ini (James \& Arroba, 1999).

Ketika ada ketidakseimbangan antara tantangan, dengan kapasitas seorang individu akan dapat menimbulkan stress. Sementara itu, stres kerja dapat dihindari ketika ada kombinasi yang seimbang antara kemampuan individu dan tuntutan kerjanya juga keseimbangan dengan lingkungan kerjanya (Marican, 1996; Ross \& Altmaier, 1994).

Salah satu penyebab stres dikalangan karyawan adalah kondisi lingkungan kerja dimana karyawan tersebut bekerja. Tinggi atau rendahnya stres kerja yang dialami karyawan sebenarnya berada pada cara karyawan tersebut mempersepsikan lingkungan kerjanya. Bila kondisi lingkungan kerja dipersepsikan secara negatif atau buruk maka stres kerjanya akan tinggi, dan sebaliknya jika karyawan mempersepsikan lingkungan kerjanya secara positif atau baik maka stres kerja yang dialami karyawan akan rendah. (Arisona,2008)

Cooper (Rini, 2002) juga menyatakan sumber stres kerja adalah berasal dari kondisi pekerjaan, masalah peran, hubungan interpersonal, kesempatan pengembangan karir, dan struktur organisasi. Kondisi pekerjaan disini, yaitu meliputi lingkungan kerja, overload, deprivational stress, dan pekerjaan yang mempunyai resiko tinggi.

Sedangkan menurut Niosh (Widhiastuti, 2002) penyebab stres kerja ada dua, yaitu : Diri individu seperti usia, kondisi fisik, dan faktor kepribadian dan faktor diluar individu seperti lingkungan, baik lingkungan keluarga maupun lingkungan kerja, dan cita-cita atau ambisi. Lingkungan mendorong kondisi kerja penuh dengan stres yang dapat langsung mempengaruhi keamanan pekerja dan kesehatan.

Penelitian menunjukkan cahaya yang memiliki dampak yang mendalam pada orang-orang terhadap kesehatan fisik, fisiologis, dan psikologis, dan pada kinerja mereka secara keseluruhan, khususnya di tempat kerja. Namun, meskipun memiliki pemahaman intuitif tentang pentingnya cahaya, serta data berbasis penelitian yang membuktikan arti pentingnya, kita sering gagal untuk memberikan pertimbangan yang memadai ketika merencanakan untuk tempat kerja. Banyak elemen lain yang kita anggap remeh, seperti udara dan tentang pencahayaan. Banyak yang menganggap itu sudah dirancang dan direncanakan untuk menyediakan hasil yang terbaik. Sayangnya, walaupun ada 
perkembangan yang signifikan dalam teknologi pencahayaan, banyak yang belum diterapkan untuk mendukung bagaimana orang saat ini bekerja.

Oleh karena itu, dengan memperhatikan lingkungan kerja dari sudut pandang ergonomi yang benar, seorang pekerja dapat merasakan kenyamanan, sehat dan lebih produktif. Jika perusahaan tidak memperhatikan ketidaknyamanan lingkungan, pekerja akan bertindak atau berusaha beradaptasi dengan mengurangi ketidaknyamanan yang ditimbulkan lingkungannya. Sebagian besar peneliti setuju bahwa stres kerja disebabkan oleh pekerjaan dan lingkungan kerja. Smith (1994) stres dinyatakan sebagai apa yang terjadi ketika tubuh tidak berhasil menyesuaikan dengan beberapa stimulus internal atau eksternal baru.

Ket de Vries (1979) menunjukkan bahwa stres adalah hasil dari ketidakseimbangan antara tuntutan lingkungan dan kemampuan individu untuk beradaptasi. Sifat dan efek stress mungkin lebih dapat dimengerti dengan mengatakan bahwa ketika beberapa variabel lingkungan (stressor) diinterpretasikan oleh individu, dapat mengakibatkan stres (Dua, 1994).

Berdasarkan penelitian Steelcase (1999), ketika individu berpikir tentang pencahayaan di tempat kerja, hal pertama yang terlintas dalam pikiran adalah efek fisik yang dapat terjadi pada diri kita. Pencahayaan yang tidak tepat dapat menyebabkan sejumlah masalah, mulai dari kelelahan mata. Bahkan, lebih dari dua pertiga dari mereka menanggapi Steelcase Workplace Survey (April 1999) mengindikasikan bahwa mereka mengalami masalah fisik yang serius yang berhubungan dengan kondisi lingkungan kerja yang buruk. Ini merupakan hasil yang konsisten dengan apa yang telah dikatakan dalam studi dan survei selama bertahun-tahun.

Seperti yang telah disampaikan di atas bahwa dampak fisik dari pencahayaan jelas terlihat, dampak fisiologis dan psikologis dari pencahayaan ini bisa sama kuat. Cahaya mengirimkan pesan visual yang dapat mempengaruhi tingkat suasana hati dan motivasi. Cahaya juga dapat mempengaruhi jam biologis dari karyawan. Hal ini dapat dilihat dari irama sirkadian (circadian rhythm), seperti waktu bangun tidur atau siklus kerja, dipengaruhi oleh cahaya. Banyak wisatawan bisnis menggunakan melatonin dalam bentuk tablet untuk membantu mereka mempertahankan efisiensi kerja mereka dan performa mereka ketika mereka melakukan perjalanan ke lokasi dalam zona waktu yang berbeda. Tetapi kebanyakan orang tidak menyadari bahwa hanya meningkatkan eksposur mereka terhadap cahaya juga bisa membantu mereka alami mengubah tingkat melatonin mereka (Steelcase,1999).

Selanjutnya Lianto \& Kurniawan juga menjelaskan bahwa penerangan yang terlalu besar membuat rasa panas dan menimbulkan kegelisahan, sebaliknya penerangan yang kurang dapat mempengaruhi aspek fisiologis pekerja seperti mengantuk dan dapat mempengaruhi konsentrsi kerja yang menimbulkan kesalahan kerja yang tinggi. 
Berdasarkan diskusi di atas, stress adalah masalah di lingkungan kerja yang tidak dapat diabaikan. Interaksi antara lingkungan kerja dan desain tempat kerja akan memberikan kontribusi pada stres kerja, salah satunya intensitas pencahayaan di ruangan. Penelitian ini ingin mengetahui apakah terdapat pengaruh pencahayaan dalam ruangan terhadap stres kerja pada karyawan di ruang perencanaan dan kerjasama Biro Rektor USU.

\section{METODE PENELITIAN}

Penelitian menggunakan PreEksperimental Design dengan jenis OneGroup Pretest-Posttest Design, dimana jenis penelitian ini tidak menggunakan kelompok kontrol. Shadish, Cook, \& Campbell (2002) menyatakan bahwa pada One-Group Pretest-Posttest Design, Pretest dilakukan terhadap kelompok subjek penelitian, setelah itu diberikan treatment, kemudian dilakukan posttest dengan pengukuran yang sama. Kelompok yang dikenai Pretest dan Posttest adalah kelompok yang sama (within subject design). Pretest dilakukan dengan memberikan skala stres kerja dan instruksi. Sedangkan treatment yang diberikan berupa penambahan intensitas pencahayaan ruang kerja. Lalu, setelah satu minggu diberikan posttest dengan memberikan skala stres kerja dengan instruksi yang sama dengan pada saat memberikan pretest.

Sampel yang digunakan adalah keseluruhan dari populasi penelitian, yaitu 13 orang karyawan di Biro Perencanaan dan Kerjasama Universitas
Sumatera Utara. Metode pengumpulan data menggunakan skala stres kerja dan alat lux meter untuk mengukur intensitas pencahayaan dalam satuan lux. Skala stres kerja disusun berdasarkan gejala stress kerja yang dibagi oleh Carry Cooper dan Alison Straw (1995) menjadi tiga yaitu: gejala fisik, gejala psikologis dan gejala perilaku. Skala stres kerja berjumlah 44 item dengan koefisien reliabilitas $=0,924$, indeks daya beda item berkisar antara 0,318 - 0,759.

Analisa data menggunakan t-test (paired samples $t$-test) dengan tingkat kemaknaan $(\alpha)=0.05(\mathrm{p}<0.5)$. Data yang dibandingkan adalah data sebelum dan sesudah treatment, dimana treatment disini adalah penambahan intensitas cahaya ruang kerja yang semula 249.7 lux menjadi 351.3 lux. Hasil pengukuran tersebut dibandingkan untuk menguji hipotesa penelitian.

\section{HASIL DAN PEMBAHASAN}

Peneliti membandingkan stres kerja subjek penelitian sebelum dan sesudah treatment yang dilakukan, yaitu penambahan intensitas pencahayaan ruang kerja dalam satu kelompok yaitu kelompok treatment dalam penelitian ini. Penambahan intensitas pencahayaan disini dilakukan dengan menambahkan jumlah lampu pada ruang kerja subjek penelitian. Menurut Cox (1993), stres kerja dapat dipahami sebagai keadaan psikologis yang merupakan hasil dari persepsi seseorang terhadap ketidakseimbangan antara tuntutan pekerjaan dan kemampuan mereka untuk mengatasi tuntutan tersebut. 
Cooper (Rini, 2002) juga menyatakan sumber stres kerja adalah berasal dari kondisi pekerjaan, masalah peran, hubungan interpersonal, kesempatan pengembangan karir, dan struktur organisasi. Kondisi pekerjaan disini, yaitu meliputi lingkungan kerja, overload, deprivational stress, dan pekerjaan yang mempunyai resiko tinggi. Kondisi lingkungan kerja yang baik ditandai oleh baiknya peredaran udara yang cukup, penerangan lampu yang terang dan jauh dari kebisingan suara yang mengganggu konsentrasi kerja, tata ruang yang baik dan warna yang indah, serta kebersihan yang terjaga sangat membuat karyawan betah bekerja. Jadi pencahayaan ruang kerja merupakan salah satu faktor yang berpengaruh terhadap stress kerja.

Perubahan stres kerja karyawan dapat dilihat dari perubahan skor stres kerja sebelum dilakukan penambahan intensitas pencahayaan ruang kerja dengan sesudah dilakukan penambahan intensitas pencahayaan ruang kerja dengan menambah jumlah lampu sehingga intensitas cahaya yang didapat sebesar 351.32 lux sehingga sesuai dengan standar pencahayaan yang direkomendasikan IES (1982). Hasil penelitian menunjukkan bahwa ada pengaruh pencahayaan ruang kerja terhadap stress kerja karyawan Biro Perencanaan dan Kerjasama Universitas Sumatera Utara. Kesimpulan ini diperoleh dari analisa paired sample t-test dengan nilai $\mathrm{p}=0.000$ dimana $\mathrm{p}<0.05$.

Dari hasil uraian tersebut maka dapat dikatakan bahwa hipotesa yang mengatakan ada perbedaan stres kerja karyawan sebelum dan sesudah dilakukan penambahan intensitas pencahayaan ruang kerja (Ha) diterima/gagal ditolak. Dapat dilihat bahwa stres kerja yang terjadi pada subjek penelitian menurun ketika pengukuran kedua dilakukan yaitu setelah penambahan intensitas pencahayaan dalam ruang kerja yang dilakukan. Adanya pengaruh pencahayaan ruang kerja terhadap stres kerja pada subjek penelitian diakibatkan penambahan intensitas pencahayaan yang dilakukan membantu mengurangi penurunan faktor fisik dan faktor psikologis yang mempengaruhi stress kerja.

Hasil penelitian diatas sesuai dengan pendapat Nitisemito (1982) yang menyatakan salah satu faktor lingkungan kerja fisik yang penting adalah penerangan. Penerangan dalam suatu lingkungan kerja ditentukan oleh tingkat intensitas cahaya. Penerangan lingkungan kerja harus diatur cukup dan sesuai dengan karakteristik pekerjaan yang sedang dilakukan, karena lingkungan fisik merupakan salah satu penyebab stres kerja. Pencahayaan merupakan salah satu komponen lingkungan fisik yang harus diperhatikan agar karyawan dapat menjalankan tuntutan pekerjaannya dengan baik dan maksimal, juga dapat bekerja dengan nyaman sehingga terhindar dari stres kerja.

\section{SIMPULAN}

Berdasarkan hasil analisis data maka dapat diambil kesimpulan bahwa terdapat pengaruh pencahayaan ruang kerja terhadap stress kerja pada karyawan di 
ruang Biro Perencanaan dan Kerjasama Universitas Sumatera Utara.

\section{UCAPAN TERIMAKASIH}

Ucapan terimakasih kepada
karyawan Biro Perencanaan dan
Kerjasama Universitas Sumatera Utara
yang telah bersedia kooperatif dan
diberikan treatment berupa penambahan
pencahayaan.

\section{DAFTAR PUSTAKA}

A, Siswanto. 1993. Penerangan. Jakarta: Balai Pelayanan Ergonomi KesKer.

Anoraga, P. \& Suyati. 1995. Psikologi Industri dan Sosial. Jakarta: Pustaka Jaya

Anshel, Jeffrey. 2005. Visual Ergonomi Handbook. CRC Press Taylor \& Francis Group.

Arisona, S. Muller, R.Adams, Gibson S. 2008. Transdisciplinary Digital Art: Sound, Vision and the New Screen. Communications in Computer and Information Science (CCIS), Volume 7, Springer Berlin Heidelberg.

Azwar, S. 1992. Metode Penelitian. Yogyakarta : Pustaka Pelajar Offset.

Azwar, S. 2005. Validitas dan Reliabilitas. Yogyakarta : Pustaka Pelajar Offset.

Beehr, TA, \& Newman, JE. 1978. Job Stress, Employee Health and Organizational Stres Kerja, Kesehatan Karyawan dan Organisasi Effectiveness: A Facet Analysis, Model and Literature Review. Personnel Efektivitas: Sebuah Model Facet, Analisis dan Pembahasan Sastra Personil. Psychology. Psikologi. 31: 665-699. 31: 665-699.

Ching, Poon, dkk. 2002. Jurnal Working Environment and Stress: A survey on Malaysian Employees in Commersial Banks.

Grandjean, E. 1988. Fitting the Task To the Man. A Texbook of Occupational Ergonomics, $4^{\text {th }}$. Edition London: Taylor \& Francis.

Hadi, S. 2001. Metodologi Research. Yogyakarta : Andi Offset

Kim, James \& Tanya Aroba. 1999. Energizing the workplace: a strategic response to stres. University Press,Cambridge.

Luthans, F. 1992. Organizational Behavior (6th ed.). Singapore: McGraw-Hill, Inc.

Makhbul, Safir Mohamed. 2007 . Ergonomics design on the work stress outcomes Jurnal Kemanusiaan bil.9.

Moekijat. 1989. Manajemen Kepegawaian. Bandung: Mandar Maju.
Mustafa Pulat,B. Fundamentals of Industrial Ergonomics. Prentice Hall International Series in Industrial and Systems Engineering.

Rafaeli et al., Emotion in work settings. Faculty of Industrial Engineering and Management Technion - Israel Institute of Technology

Rice, P. L. 1999. Stress and Health (3rd ed.). California: Brooks/Cole Publishing Company.

Selye, H. 1956. The Stress of Life. New York : McGraw Hill.

Soewarno. 1992. Penerangan Tempat Kerja. Jakarta: Pusat Pelayanan Ergonomi dan kesker

SteelCase. 1999. Seeing the Difference : The Importance of Quality Lighting in the Workplace. SteelCase. Inc.

Suma'mur PK. 1993. Higiene Perusahaan dan Kesker. Jakarta: CV. Haji Masagung

Suma'mur, PK. 1996. Ergonomi Untuk Produktivitas Kerja, Jakarta: CV. Haji Masagung. 